\title{
Critical race theory in medicine
}

\author{
Cite as: CMAJ 2021 May 17;193:E739-41. doi: 10.1503/cmaj.210178
}

CMAJ Podcasts: author interview at www.cmaj.ca/lookup/doi/10.1503/cmaj.210178/tab-related-content

n Sept. 4, 2020, the Executive Office of the President of the United States issued a memorandum to US government agencies to cease and desist any funding of employee training related to critical race theory or "White privilege" or both, deeming these to be "anti-American" and "divisive." 1 Ironically, this pushed critical race theory into public discourse - it was even a point of discussion in the first US presidential debate, where education based on critical race theory was described as a "radical revolution."

As Black and Brown women in medicine, we have found in critical race theory a language with which we can better understand our experiences. Critical race theory gave me (R.Z.) the tools to found Black Physicians of British Columbia (www.blackphysiciansofbc.ca) and to work toward change in my own institution. It helped me (M.S.) "unlearn" some of the ways in which I was taught about race during medical training, where race was understood as a biological fact rather than as a social construct that maintains long-standing power relations. Medical education certainly did not offer me the conceptual tools to approach racism.

Critical race theory emanated from years of advocacy by Black and Brown lawyers in the US faced with racist lawschool hiring practices and curricula. ${ }^{2,3}$ Deeply rooted in theory-informed action, critical race theory can be used to understand the structural forces that drive racial inequities in society, and to work toward their dismantling. ${ }^{2}$ Studying race and racism, even structurally, is insufficient and must be coupled with tangible action at multiple levels. ${ }^{4}$

Critical race theory is organized around 4 main ideas, referred to by the

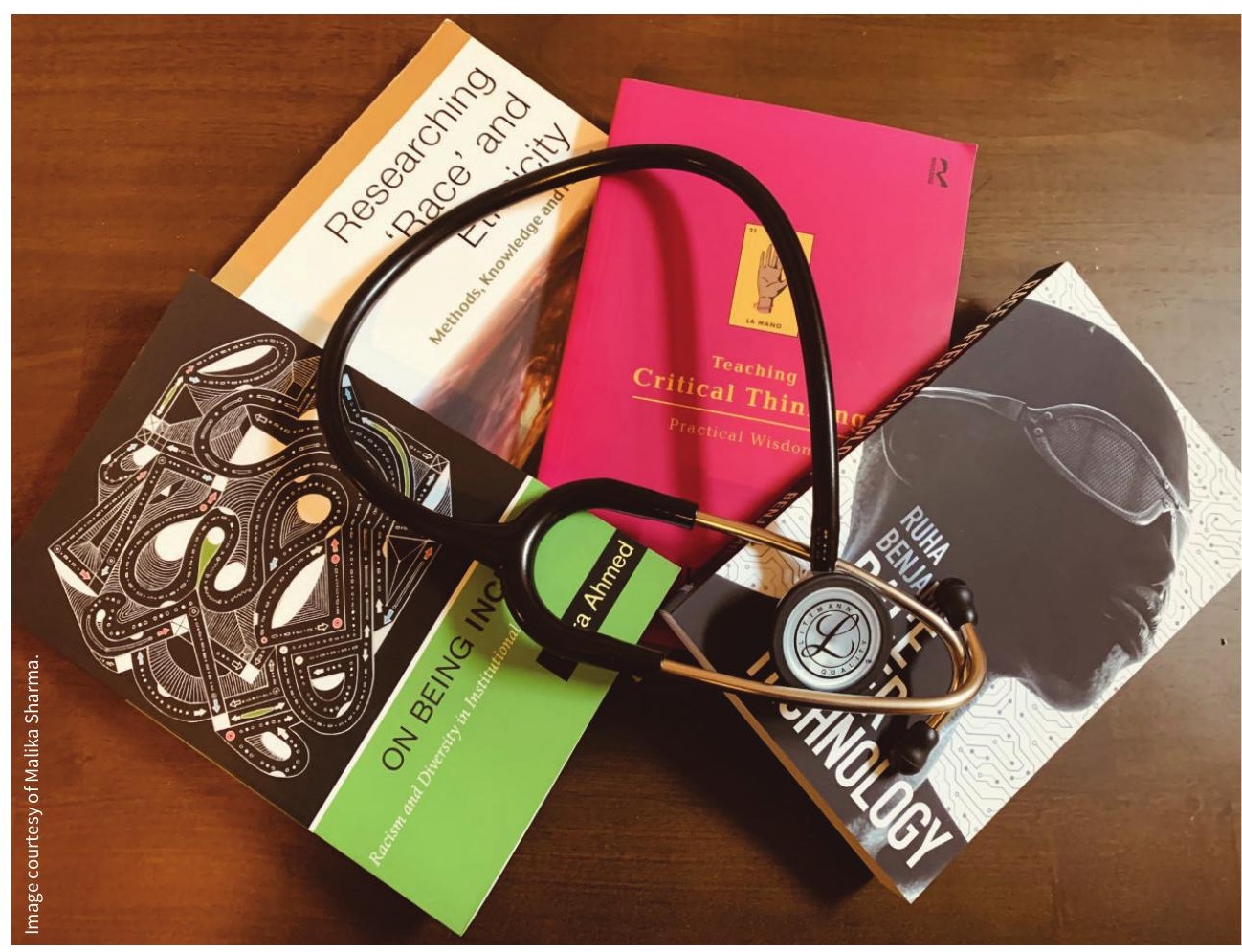

terms "race consciousness," "contemporary orientation," "centring the margins" and "praxis."

Race consciousness refers to an understanding of racialization, or the creation of "race" as a social process that assigns meaning and value to physical and cultural differences between people. Race consciousness requires us to examine what we take for granted about race and racism, asking ourselves how they have shaped individual and interpersonal interactions, and our institutions and societies. ${ }^{4}$ In medicine, it means thinking critically about what makes it possible to perceive race as a biological fact, and why it is so easy to use race as an explanation for health differences between people while overlooking the effects of political and social forces. Racism has been integrated into ity of numbers (like "race corrections" for physiologic measures), and through the things we overlook every day in clinical practice. ${ }^{5}$ Critical race theory forces us to reassess the racist practices we take for granted and the policies we perceive as "neutral." For example, routinely obtaining a history from patients without seeking professional translation services when there is language discordance between patient and provider is wholly inadequate care, yet widely accepted. This practice disproportionately affects racialized people and families. ${ }^{3}$

In the context of critical race theory, "centring the margins" means shifting our focus from the dominant group to those who have been pushed to the margins. ${ }^{2}$ It medicine through the apparent objectiv- 
means valuing the expertise of people who have been marginalized and oppressed, in addressing inequities and creating new alternatives.

A growing body of medical scholarship informed by critical race theory, published over the past decade, has shed light on how racism affects the way physicians care for patients from primary care to rheumatology and obstetrics. ${ }^{2,4,6-8}$ However, there has been little discussion of how critical race theory can be woven into the very fabric of the medical profession.

\section{Medical education}

By framing race as a social construct, clinical teachers can foster race consciousness to avoid perpetuating harmful stereotypes, such as beliefs that Black bodies are more "pain tolerant," a misconception that has resulted in inappropriate analgesic recommendations for many patients. ${ }^{9}$ Medical school curricula can critically unpack the way "race" is used as a proxy marker for the structural roots of health problems such as poverty, and differential access to health care and education. However, the use of race as a proxy marker without attending to structural issues reinforces harmful and incorrect assumptions.

Clinicians can "centre the margins" by actively seeking and placing value on the knowledge and perspectives of racialized patients, learners and fellow educators. Recently, medical students have proven their ability to effect change in a global, student-led movement to better represent racialized people in dermatology teaching materials. ${ }^{10}$

\section{Clinical care}

Critically examining the paucity (and even veracity of) evidence for race-based clinical decisions is essential. Just one example is questioning the logic behind recommending diuretics for East African-Canadian patients based on clinical trials involving African-American participants of primarily West African descent. ${ }^{11}$

The stark racial disparities seen in morbidity and mortality related to COVID19 and access to SARS-CoV-2 vaccines have highlighted systemic barriers some groups face when accessing the medical system. Praxis, or theory-informed action, urges clinicians to move beyond mere recognition of racism to intervening to eliminate race-based health disparities. Targeted public health campaigns such as a recent initiative by the Black Doctors COVID Consortium, to vaccinate Black community members who work long hours or have difficulty accessing online registration, can help minimize barriers to medical care and slowly rebuild trust in the health care system. ${ }^{12}$

\section{Racism in the workplace}

Racialized health care workers face microaggressions and other forms of everyday racism at work. In Ontario, 70\% of Black physicians frequently experience race-based discrimination, including being mistaken for custodial staff, receiving unsolicited comments about their hair, being ignored for promotions or having their competency questioned. ${ }^{11}$ Such "ordinariness" of everyday racism puts a heavy burden on racialized physicians to prove to colleagues, supervisors and disciplinary bodies how racism affects them personally at work. Critical race theory prompts reflection on the structural foundations underpinning these everyday experiences and action to address them. Rather than everyday racism being disregarded as isolated, minor incidents, critical race theory encourages centring of the experiences of racialized trainees and physicians and shifts focus from intention to impact. It can drive measures such as reviewing and modifying hiring practices and training programs, and the creation of communities of support to foster safe and inclusive workplaces.

\section{Research}

Historical examples like the Tuskegee syphilis study in the US, malnutrition experiments involving Indigenous children in Canada in residential schools, and research based on assumptions that Indigenous people were physiologically "prone" to tuberculosis have done little to engender the confidence of racialized people in medical research. Medical logic continues to locate "vulnerability" to disease in the bodies of racialized peoples, as seen in recent attempts to associate genetic polymorphisms with higher rates of COVID-19 among Black Americans. ${ }^{13}$ Critical race theory fosters a shared responsibility to go beyond such reductionistic models of health and sickness and examine the social forces that drive race-based inequities.

\section{Conclusion}

The medical profession faces increasing calls to address racism and promote equity, diversity and inclusion. Critical race theory, recently brought to the forefront of public discussion, represents a powerful tool for change. This is indeed a "radical revolution" whose time has come.

\section{Rahel Zewude MD}

Department of Medicine, University of British Columbia, Vancouver, BC

\section{Malika Sharma MD MEd}

Division of Infectious Diseases,

Department of Medicine, St. Michael's Hospital; Assistant Professor, University of Toronto, Toronto, Ont.

\section{References}

1. Vought R. M-20-34: Memorandum for the heads of executive departments and agencies. Washington (DC): Executive Office of the President, Office of Management and Budget; 2020 Sept. 4. Available: www.whitehouse.gov/wp-content/ uploads/2020/09/M-20-34.pdf (accessed 2020 Oct. 9).

2. Ford CL, Airhihenbuwa CO. Critical Race Theory, race equity, and public health: toward antiracism praxis. Am J Public Health 2010; 100(Suppl 1):S30-5.

3. Bell DA. David C. Baum Memorial Lecture: Who's afraid of Critical Race Theory? 1995 U. Ill. Law Rev 99994. Champaign (IL): Illinois College of Law; 1995:893.

4. Ford CL, Airhihenbuwa CO. The public health critical race methodology: praxis for antiracism research. Soc Sci Med 2010;71:1390-8.

5. Vyas DA, Eisenstein LG, Jones DS. Hidden in plain sight: reconsidering the use of race correction in clinical algorithms. N Engl J Med 2020;383:874-82.

6. Williams JN, Ford CL, Morse M, et al. Racial disparities in rheumatology through the lens of Critical Race Theory. Rheum Dis Clin North Am 2020;46:605-12.

7. Adebayo CT, Parcell ES, Mkandawire-Valhmu L, et al. African American Women's maternal healthcare experiences: a Critical Race Theory perspective. Health Commun 2021 Feb. 18 [Epub ahead of print]. doi: 10.1080/10410236.2021 .1888453.

8. Cunningham A, Crittendon D, Konys C, et al. Critical Race Theory as a lens for examining primary care provider responses to persistently-elevated 
HbA1c. J Natl Med Assoc 2020 Dec. 17 [Epub ahead of print]. doi: 10.1016/j.jnma.2020.11.012.

9. Hoffman KM, Trawalter S, Axt JR, et al. Racial bias in pain assessment and treatment recommendations, and false beliefs about biological differences between blacks and whites. Proc Natl Acad Sci U S A 2016;113:4296-301.

10. Medical schools must include BAME representation in clinical teaching. Change.org. Available: www. change.org/p/gmc-medical-schools-must-include -bame-representation-in-clinical-teaching?signed =true (accessed 2021 Mar. 25).

11. Mpalirwa J, Lofters A, Nnorom O, et al. Patients, pride, and prejudice: exploring Black Ontarian physicians' experiences of racism and discrimination. Acad Med 2020;95:S51-7.

12. Ralph $P$. Thousands of Philly residents inoculated at 24-hour COVID-19 vaccine clinic. PhillyVoice 2021 Feb. 21. Available: www.phillyvoice.com/ black-doctors-covid-19-consortium-vaccination -site-philadelphia/ (accessed 2021 Mar. 16).

13. Phillips N, Park I-W, Robinson JR, et al. The perfect storm: COVID-19 health disparities in US Blacks. J Racial Ethn Health Disparities 2020 Sept. 23 [Epub ahead of print]. doi: 10.1007/s40615-020-00871-y.

This article has been peer reviewed.

Competing interests: None declared.

Content licence: This is an Open Access article distributed in accordance with the terms of the Creative Commons Attribution (CC BY-NC-ND 4.0) licence, which permits use, distribution and reproduction in any medium, provided that the original publication is properly cited, the use is noncommercial (i.e., research or educational use), and no modifications or adaptations are made. See: https://creativecommons.org/ licenses/by-nc-nd/4.0/ 